\title{
A Psychological Study of Anxiety among Diabetic challengers
}

\author{
Chauhan Ajay* \\ Department of Psychology, Saurashtra University, India
}

Submission: April 22, 2017; Published: April 28, 2017

*Corresponding author: Chauhan Ajay, Department of Psychology, Saurashtra University, India, Tel: 9197276 26080; Email: psy.ajchauhan@gmail.com

Abstract

Background: Anxiety has been shown to be associated with poor outcomes in people with diabetes. However, there has been limited data, especially from India, which has specifically examined whether diabetes mellitus is associated with an increased likelihood of comorbid anxiety. The study was intended to examine the effect of Anxiety on diabetic challengers.

Aim: The aim was to estimate the prevalence of anxiety in patients with diabetes and to determine the association of anxiety with area and gender.

Sample: The sample consists of 160 diabetic patients from different hospital in Rajkot district area. The sample was selected from randomly.

Design: $2 * 2$ research design was used the present study.

Tools: Anxiety was measured through a questionnaire 'Sinha's Comprehensive Anxiety Test (SCAT) was used. Test developed by A.K.P Sinha and L.N.K Sinha in (1995). The data was analyzed by the $t$ test.

Results: There will be no significant difference between Gender and Types of Area in relation to their Anxiety.

Conclusions: Our study demonstrates a higher prevalence of anxiety in diabetic challengers. No factor was significantly associated with anxiety.

Keywords: Anxiety; Diabetic challengers

\section{Introduction}

\section{Anxiety is defined as}

I. A state of uneasiness, apprehension; as about future uncertainties.

II. A state of apprehensiohn, uncertainty, and fear resulting from anticipation of a realistic or fantasized threatening event or situation, often impairing physical and psychological functioning. David Barlow [1] defines anxiety as "a futureoriented mood state in which one is ready or prepared to attempt to cope with upcoming negative events," and that it is a distinction between future and present dangers which divides anxiety and fear. In other words, anxiety occurs when we behave (think and act) in an apprehensive manner, such as when worrying about an event or situation.

The philosopher Soren Kierkegaard, in The Concept of Anxiety (1844), described anxiety or dreads associated with the "dizziness of freedom" and suggested the possibility for positive resolution of anxiety through the self-conscious exercise of responsibility and choosing. The psychologist Otto Rank. In Art and Artist (1932) wrote that the psychological trauma of birth was the pre-eminent human symbol of existential anxiety and encompasses the creative person's simultaneous fear of and desire for separation, individuation and differentiation.

The theologian Paul Tillich characterized existential anxiety as "the state in which a being is aware of its possible nonbeing" and he listed three categories for the nonbeing and resulting anxiety: on tic (fate and death), moral (guilt and condemnation), and spiritual (emptiness and meaninglessness). According to Tillich, the last of these three types of existential anxiety, i.e. spiritual anxiety, is predominant in modern times while the others were predominant in earlier periods. Tillich argues that this anxiety can be accepted as part of the human 
condition or it can be resisted but with negative consequences. In its pathological form, spiritual anxiety may tend to "drive the person toward the creation of certitude in systems of meaning which are supported by tradition and authority" even though such "undoubted certitude is not built on the rock of reality".

According to Viktor Frankl, the author of Man's Search for Meaning, when a person is faced with extreme mortal dangers, the most basic of all human wishes is to find a meaning of life to combat the "trauma of nonbeing" as death is near. Anxiety is a physiological and psychological state characterized by cognitive, somatic, emotional and behavioral components. These components combine to create an unpleasant feeling that is typically associated with uneasiness, apprehension, or worry.

Anxiety is a generalized mood state that occurs without an identifiable triggering stimulus. As such, it is distinguished from fear, which occurs in the presence of an external threat. Additionally, fear is related to the specific behaviors of escape and avoidance, where as anxiety is the results of threats that are perceived to be uncontrollable or unavoidable. Anxiety is a term used to describe uncomfortable feeling of nervousness, worry and tension which we all feel from time to time. Anxiety can affect anyone, whatever their age, gender etc., It affects our thoughts, physical reactions, moods and behavior. Anxiety can also cause us to feel panicky and frightened and prevent us from doing things. Too much stress in our lives can result in higher levels of anxiety. We know from research that at any one time, there are many people experiencing anxiety that is a problem to them. Anxiety can either be very general; affecting many areas of our lives or it may be more specific to certain situations such as crowded places, travelling on buses. It could even occur as a specific phobia such as a fear of lifts or a fear of spiders.

\section{Anxiety affects us in four main ways}

I. Physical effects: When we are anxiety we will fear many physical symptoms of anxiety, such as a pounding heart, a churning stomach, or breathing difficulties. Long term stress also affects us physically.

II. Thoughts: When we are anxiety we tend to worry and have negative thoughts. Like 'when if I make a fool of myself or what if I suffocate/faint/have a heart attack.' As well as thoughts we may experience images or pictures in our mind such as images of a car crash or someone criticizing us.

III. Mood: Anxiety itself is a type of mood. Anxiety and prolonged stress can also affect our moods in other ways. For example, it we experience anxiety that restricts our lives over a long period of time, we may feel guilty, down and depression.

IV. Behavior: Anxiety also affects our behavior changing the things we feel able to do. This can result in avoidance of many things, such as going into a supermarket or going to the dentist. When we can't avoid things we may do things to make us feel safe, such as always having someone with us, or carrying tablets that we don't really need.

\section{Common Symptoms}

Anxiety symptoms may be different based on the particular condition or disorder, but common symptoms include:

i. Excessive, irrational, or uncontrollable feelings of worry and dread

ii. Sensations of panic and uneasiness for no apparent reason
iii. Obsessive thoughts
iv. Ritualistic behavior
v. Trouble sleeping
vi. Heart palpitations
vii. Muscle tension
viii. Inability to remain calm

ix. Nausea

x. Headaches

xi. Fatigue

xii. Trouble concentrating

xiii. Rapid breathing, or hyperventilation

xiv. Sweating

xv. Dry mouth

xvi. Dizziness

xvii. Cold or sweaty hands and feet

xviii. Trembling or shaking

xix. Stomachache

\section{Review of Literature}

\section{Study-1}

I. Problem: 'Anxiety among Diabetic and non-Diabetic Male \& Female'

II. Researcher: Dr. Krishna J. Vaghela [2]. The present research was to study the anxiety level among diabetic and non-diabetic people (both male and female). The study was conducted over a sample of 160 people (80- male: 40 diabetic and 40 on diabetic as well as 80 -female: 40 diabetic and 40 non diabetic). For the purpose of the measuring anxiety level of participants the Beck anxiety inventory was used. The obtained data were analyzed and interpreted on using statistical tools such as mean, standard deviation, and $\mathrm{t}$ - test. The results reported that statistically significant difference observed among diabetic and non-diabetic male 
participants in relation to anxiety their level. As regarding to female participants with diabetic and non-diabetic also significantly differ on their scores on anxiety. In conclusion the anxiety level was significantly higher in diabetic people both: male as well as female.

\section{Study-2}

I. Problem: 'A Study of Academic Anxiety of Secondary School Students With Relation To Their Gender and Religion'

II. Researcher: Dr. Arvindgiri K. Aparnath [3-5]. The present study is based on Academic anxiety. The aim of the study is to find out the difference between religion and gender, regarding academic anxiety for the purpose of the study, 120 School children were chosen from different school at Kapadwanj town, Gujarat, for data collection in all 120 student, 60 being boys ( $30 \mathrm{Hindu}+30$ Muslim) and 60 girls (30 Hindu +30 Muslim).

Generally anxiety can be either a trait anxiety or a state anxiety. A trait anxiety is a stable characteristic or trait of the person. A state anxiety is one which is aroused by some temporary condition of the environment such as examination, accident, punishment, etc. Academic anxiety is a kind of state anxiety which relates to the impending danger from the environments of the academic institution including teacher, certain subjects like Mathematics, English, etc. I have used Academic Anxiety Scale for children" (AASC Scale) by Dr. A. k. Singh \& Dr. (km) A. Sen Gupta. The obtained data analyzed through Mann- Whitney „U "test. The result shows that there was no significant difference between the Academic anxiety of Muslim boys \& girls and Hindu girls \& Muslim girls. There is more Academic anxiety in Hindu girls then Hindu boys and more Academic anxiety in Muslim boys then Hindu boys.

\section{Objectives}

This present study aims to investigate the effect of diabetic Challengers anxiety. The study has the following specific objectives in view:

i. To compare the Anxiety among Diabetic Challengers.

ii. To compare the Anxiety of urban areas diabetic challengers.

iii. To compare the Anxiety of Rural areas diabetic challengers.

iv. To compare the Anxiety of urban areas male and female diabetic challengers.

v. To compare the Anxiety of rural areas male and female diabetic challengers.

vi. To compare the Anxiety of urban and rural areas male diabetic challengers. vii. To compare the Anxiety of urban and rural areas female diabetic challengers.

\section{Hypothesis}

The following hypotheses were framed for the purpose of present study:

A. There will be no significant difference on Anxiety of urban and rural areas diabetic challengers.

B. There will be no significant difference on Anxiety of urban areas male and rural areas female diabetic challengers.

C. There will be no significant difference on Anxiety of urban areas female and rural areas male diabetic challengers.

D. There will be no significant difference on Anxiety of urban areas and rural areas male diabetic challengers.

E. There will be no significant difference on Anxiety of urban and rural areas female diabetic challengers.

\section{Methodology (Table 1)}

Table 1: Variable in the study major variables as per following.

\begin{tabular}{|c|c|c|c|c|c|}
\hline & No. & Variable & $\begin{array}{c}\text { Types of } \\
\text { Variable }\end{array}$ & Level & $\begin{array}{c}\text { Name of } \\
\text { the Level }\end{array}$ \\
\hline 1. & Area & 2 & Independent & $\bullet$ & Urban \\
\hline$\bullet$ & Rural & & & & \\
\hline 2. & Gender & 2 & Independent & $\bullet$ & Male \\
\hline$\cdot$ & Female & & & & \\
\hline 3. & Anxiety & 1 & Dependent & & \\
\hline
\end{tabular}

\section{Sample}

Total sample comprised of 160 diabetic challengers, 80 of rural areas and 80 of urban areas diabetic challengers were included in the sample. Further, sample was bifurcated according to gender (40 male and 40 female). The diabetic challengers were selected from Rajkot district areas (Table 2).

Table 2: Gender wise distribution of the sample.

\begin{tabular}{|c|c|c|c|}
\hline \multicolumn{2}{|c|}{ Rural } & \multicolumn{2}{c|}{ Urban } \\
\hline Male & Female & Male & Female \\
\hline 40 & 40 & 40 & 40 \\
\hline \multicolumn{2}{|c|}{ Total=80 } & \multicolumn{3}{c|}{ Total=80 } \\
\hline
\end{tabular}

I. Research Design: In this way, the research design happens of $2 \times 2$ factorial, which appends upon sample.

II. Tools Used: The present study Sinha's Comprehensive Anxiety Test (SCAT) was used. Test developed by A.K.P Sinha and L.N.K Sinha in (1995).

III. Reliability: Reliability of Sinha's Comprehensive Anxiety Test (SCAT): Test consists of 90 items, significant at 0.01 levels. Scoring, Sum, total scores show the anxiety level. Higher the scores show higher the anxiety. The coefficient 


\section{Global Journal of Addiction \& Rehabilitation Medicine}

of reliability was determined by using the Product moment correlation was 0.85 and by using Spearman Brown Formula was 0.92 . Both the values ensure a high reliability of the test.

IV. Validity: The coefficient of validity was 0.62 , which is significant beyond 0.01 Level of confidence.

\section{Statistical Analysis}

After collecting the response from the diabetic challengers, at first all data sheets were checked thoroughly to find out any gaps or discrepancies in the response sheets. For data analysis, descriptive statistics $t$ test was used and for the Hypothesis inferential statistical t test was used diabetic challengers.

\section{Results and Discussion}

Table 3: Shows there will be no significant difference between urban and rural areas diabetic challengers in relation to their anxiety.

\begin{tabular}{|c|c|c|c|c|c|}
\hline Area & Mean & SD & SEM & t & $\begin{array}{c}\text { Sig. } \\
\text { Level }\end{array}$ \\
\hline Urban & 50.23 & 7.76 & 0.87 & 2.7506 & 0.01 \\
\cline { 1 - 3 } Rural & 47.00 & 7.06 & 0.79 & & \\
\hline
\end{tabular}

I. There will be no significant difference on Anxiety of urban and rural areas diabetic challengers. The result of $\mathrm{t}$ test, given in (Table 3 ), show that the $\mathrm{t}$ value obtained is no significant $(t=2.7506)$, revealing the fact that the group compared do significantly with regard to their area score. Hence the null hypothesis Ho1: "There will be no significant difference on the anxiety among urban and rural area's diabetic patients" is accepted (Figure 1).

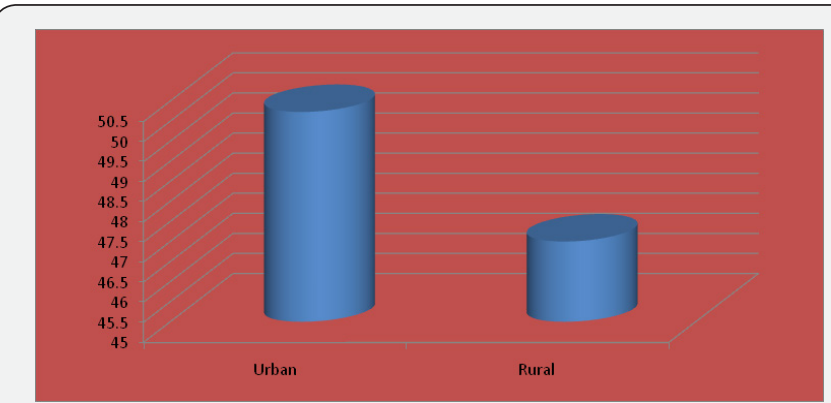

Figure 1: shows mean score of urban and rural areas diabetic challengers in relation to their anxiety.

Table 4: Shows there will be no significant difference between urban areas male and rural areas female diabetic challengers in relation to their anxiety.

\begin{tabular}{|c|c|c|c|c|c|}
\hline Area & Mean & SD & SEM & t & $\begin{array}{c}\text { Sig. } \\
\text { Level }\end{array}$ \\
\hline $\begin{array}{c}\text { Urban } \\
\text { (M) }\end{array}$ & 51.73 & 8.01 & 1.27 & 1.5114 & 0.01 \\
\cline { 1 - 3 } Rural (F) & 48.93 & 7.36 & 1.16 & & \\
\hline
\end{tabular}

II. There will be no significant difference on Anxiety of urban areas male and rural areas female diabetic challengers. $\mathrm{df}=78$ The result of $\mathrm{t}$ test, given in (Table 4), show that the $\mathrm{t}$ value obtained is no significant $(t=1.5114)$, revealing the fact that the group compared do significantly with regard to their area's gender score. Hence the null hypothesis Ho2: "There will be no significant difference on the anxiety among urban area's male and rural area's female diabetic challengers" is accepted (Figure 2).

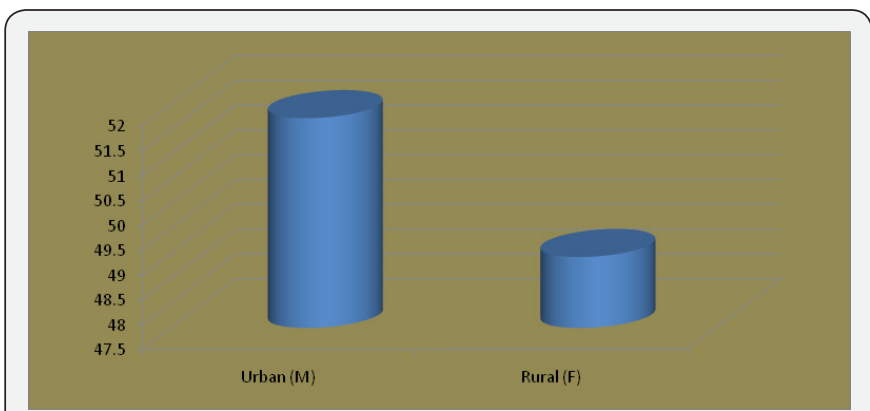

Figure 2: shows mean score of urban areas male and rural areas female diabetic challengers in relation to their anxiety.

Table 5: Shows there will be no significant difference between urban areas female and rural areas male diabetic challengers in relation to their anxiety.

\begin{tabular}{|c|c|c|c|c|c|}
\hline Group & Mean & SD & SEM & t & $\begin{array}{c}\text { Sig. } \\
\text { Level }\end{array}$ \\
\hline $\begin{array}{c}\text { Urban } \\
\text { (F) }\end{array}$ & 46.53 & 6.64 & 1.05 & 0.5995 & 0.01 \\
\cline { 1 - 3 } Rural (M) & 47.48 & 7.50 & 1.19 & & \\
\hline
\end{tabular}

III. There will be no significant difference on Anxiety of urban areas female and rural areas male diabetic challengers. $\mathrm{df}=78$ The result of $\mathrm{t}$ test, given in (Table 5 ), show that the $t$ value obtained is no significant $(t=0.5995)$, revealing the fact that the group compared do significantly with regard to their area's gender score. Hence the null hypothesis Ho3: "There will be no significant difference on the anxiety among urban area's female and rural area' smale diabetic challengers" is accepted (Figure 3).

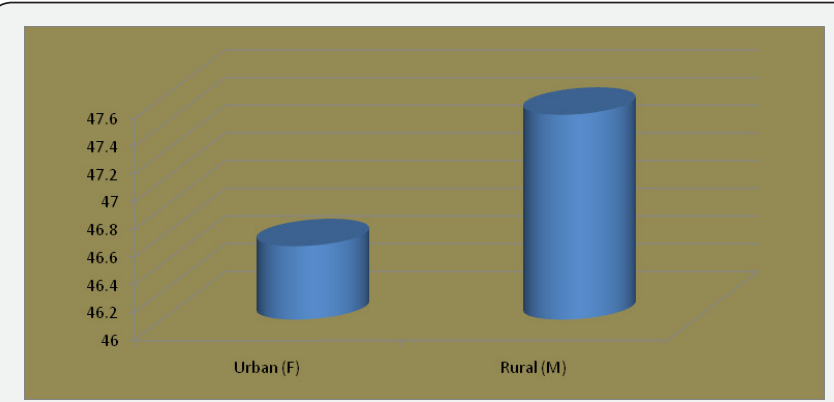

Figure 3: shows mean score of urban areas female and rural areas male diabetic challengers in relation to their anxiety.

Table 6: Shows there will be no significant difference between urban and rural areas male diabetic challengers in relation to their anxiety.

\begin{tabular}{|c|c|c|c|c|c|}
\hline Group & Mean & SD & SEM & t & $\begin{array}{c}\text { Sig. } \\
\text { Level }\end{array}$ \\
\hline $\begin{array}{c}\text { Urban } \\
\text { (M) }\end{array}$ & 49.50 & 7.98 & 0.89 & 1.4893 & 0.01 \\
\cline { 1 - 3 } Rural (M) & 47.73 & 7.07 & 0.79 & & \\
\hline
\end{tabular}

IV. There will be no significant difference on Anxiety of urban areas and rural areas male diabetic challengers. $\mathrm{df}=$ 


\section{Global Journal of Addiction \& Rehabilitation Medicine}

158 The result of $t$ test, given in (Table 6), show that the $t$ value obtained is no significant $(t=1.4893)$, revealing the fact that the group compared do significantly with regard to their area's gender score. Hence the null hypothesis Ho4: "There will be no significant difference on the anxiety among urban area and rural area male diabetic challengers" is accepted (Figure 4).

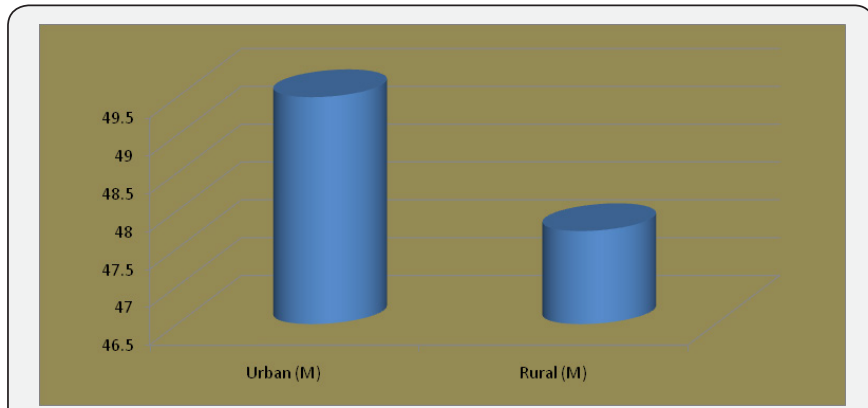

Figure 4: shows mean score of urban areas female and rural areas male diabetic challengers in relation to their anxiety.

Table 7: Shows there will be no significant difference between urban and rural areas female diabetic challengers in relation to their anxiety.

\begin{tabular}{|c|c|c|c|c|c|}
\hline Group & Mean & SD & SEM & t & $\begin{array}{c}\text { Sig. } \\
\text { Level }\end{array}$ \\
\hline $\begin{array}{c}\text { Urban } \\
\text { (F) }\end{array}$ & 47.48 & 7.50 & 1.19 & 0.5995 & 0.01 \\
\cline { 1 - 3 } Rural (F) & 46.53 & 6.64 & 1.05 & & \\
\hline
\end{tabular}

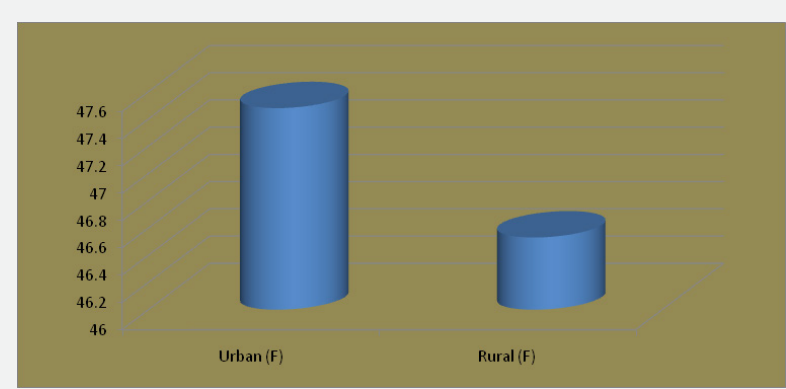

Figure 5: shows mean score of urban areas female and rural areas male diabetic challengers in relation to their anxiety.
V. There will be no significant difference on Anxiety of urban and rural areas female diabetic challengers. $\mathrm{df}=78$ The result of $t$ test, given in (Table 7 ), show that the $t$ value obtained is no significant ( $\mathrm{t}=0.5995)$, revealing the fact that the group compared do significantly with regard to their area's gender score. Hence the null hypothesis Ho5: "There will be no significant difference on the anxiety among urban area and rural area female diabetic challengers" is accepted (Figure 5).

\section{Conclusion}

I. There is no significant difference found on Anxiety of urban and rural areas diabetic challengers.

II. There is no significant difference found on Anxiety of urban areas male and rural areas female diabetic challengers.

III. There is no significant difference found on Anxiety of urban areas female and rural areas male diabetic challengers.

IV. There is no significant difference found on Anxiety of urban areas and rural areas male diabetic challengers.

V. There is no significant difference found on Anxiety of urban and rural areas female diabetic challengers.

\section{References}

1. Barlow, David H (2000) Unraveling the mysteries of anxiety and its disorders from the perspective of emotion theory. American Psychologist 55 (11): 1247-1263.

2. Vaghela K (2016) Anxiety among Diabetic and non-Diabetic Male \& Female. The International Journal of Indian Psychology 3(2): 1.

3. Aparnath A (2014) A Study of Academic Anxiety of Secondary School Students With Relation To Their Gender and Religion. The International Journal of Indian Psychology 01 (4): 2.

4. Chauhan A (2016) A Psychological study of anxiety and dear fear person among Diabetic patients, Unpublished M.Phil. Dissertation, Sardar Patel University, Vallabh Vidyanagar, India.

5. Davison, Gerald C (2008) Abnormal Psychology, Toronto: Veronica Visentin pp: 154.

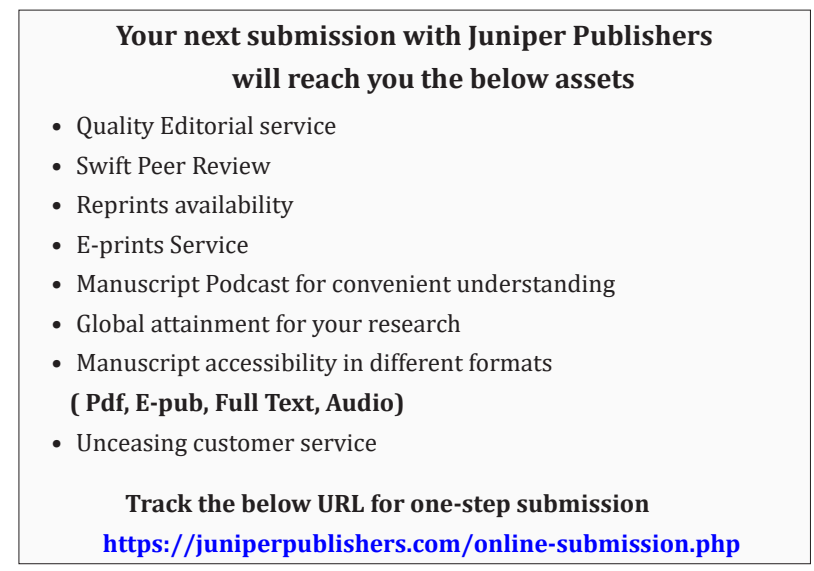

